NBER WORKING PAPER SERIES

\title{
INSURANCE AND THE UTILIZATION OF MEDICAL SERVICES AMONG THE SELF-EMPLOYED
}

\author{
Craig William Perry \\ Harvey S. Rosen \\ Working Paper 8490 \\ http://www.nber.org/papers/w8490
NATIONAL BUREAU OF ECONOMIC RESEARCH
1050 Massachusetts Avenue
Cambridge, MA 02138
September 2001

We are grateful to Brookes Billman, Sijbren Cnossen, Gebhard Flaig, Jonathan Gruber, Douglas Holtz-Eakin, Helen Levy, James Poterba, Amy K. Taylor, Diane Whitmore, and seminars at Princeton and Columbia for useful suggestions, to Karen Neukirchen for help in preparing the manuscript, and to Princeton's Center for Economic Policy Studies and the National Science Foundation for financial support. This paper was presented at the CESifo conference, "Public Finances and Public Policy in the New Millennium: A Conference on the Occasion of Richard Musgrave's 90th and CES's 10th Birthdays," in Munich on January 12-13, 2001. We thank the participants at the conference and two referees for their comments. The views expressed herein are those of the author(s) and not necessarily those of the National Bureau of Economic Research.

(C) 2001 by Craig William Perry and Harvey S. Rosen. All rights reserved. Short sections of text, not to exceed two paragraphs, may be quoted without explicit permission provided that full credit, including $\odot$ notice, is given to the source. 
Insurance and the Utilization of Medical Services Among the Self-Employed Craig William Perry and Harvey S. Rosen

NBER Working Paper No. 8490

September 2001

JEL No. I12

\begin{abstract}
$\underline{\text { ABSTRACT }}$
There has been substantial public policy concern over the relatively low rates of health insurance coverage among the self-employed in the United States. We use data from the Medical Expenditure Panel Survey conducted in 1996 to analyze how the self-employed and wage-earners differ both with respect to insurance coverage and utilization of a variety of health care services. Our results suggest that for the self-employed, the link between insurance and utilization of health care services is not as strong as assumed in the policy debate. For a number of medical care services, the self-employed have the same rates of utilization as wage-earners, despite the fact that they are substantially less likely to be insured. And when the self-employed are less likely than wage-earners to utilize a particular medical service, the differences generally do not seem very large. The self-employed thus appear to be able to finance access to health care from sources other than insurance. Further, analysis of out-of-pocket expenditures on health care suggests that doing so does not lead to substantial reductions in their ability to consume other goods and services. Finally, there is no evidence that children of the self-employed have less access to health care than the children of wage-earners. Hence, the public policy concerns that the relative lack of health insurance among the self-employed substantially reduces utilization of health care services or creates economic hardship appear to be misplaced.
\end{abstract}

Craig William Perry

Princeton University Investment Co.

22 Chambers Street

Princeton, NJ 08542

cwperry@princeton.edu
Harvey S. Rosen

Department of Economics

Princeton University

Princeton, NJ 08544

and NBER

hsr@princeton.edu 


\section{Introduction}

About 44.2 million Americans, over 16 percent of the population, lack any kind of medical insurance. This phenomenon is central to policy debates about health care. As former President Clinton observed, "This is a problem that America cannot let go." Self -employed people have received particular attention in this context because of their lower than average insurance rates - only 68 percent of those under 63 years of age had any coverage in 1996, according to our tabulations from the Medical Expenditure Panel Survey.

The principal public policy response to the situation of the self-employed has been to subsidize their purchases of health insurance through the personal income tax. Currently, self-employed workers are allowed to deduct 60 percent of their healthinsurance premiums, which is up from 45 percent in 1998. According to recent legislation, this figure is scheduled to increase to 70 percent in 2002 and 100 percent in 2003 and thereafter. ${ }^{1}$ Rules Committee Chairman David Dreir hailed the bill's passage by saying: "The American people are concerned that they can't gain access to quality health care...Accessibility is our key. We're moving toward it" (Murray and McGinley [1999]). According to news reports, insurance companies have been lobbying the congress to accelerate this schedule ${ }^{2}$, a proposal supported by Elizabeth Dole during her brief run for the Republican presidential nomination.

Congressman Dreir's statement is useful because it spells out clearly the putative reasoning behind the policy of subsidizing insurance purchases for the self-employed-

\footnotetext{
${ }^{1}$ See Internal Revenue Service Code section 162(1).

${ }^{2}$ See Wall Street Journal, October 7, 1999, p. A2.
} 
lack of insurance translates into lack of utilization of health care. ${ }^{3}$ It is, in fact, well documented that the self-employed are less likely to be insured than wage-earners, even after taking into account their differing demographic characteristics (Holtz-Eakin, Penrod, and Rosen [1996] and Hamilton [2000]). However, it is not obvious that, for this group of people, lack of insurance does indeed translate into lack of utilization of health care services. Health care, after all, can be financed from sources other than insurance. In fact, we know of no research that examines whether the self-employed utilize health services less than their wage-earning counterparts. This paper investigates the links between health insurance and utilization among the self-employed. The centerpiece of the study is a statistical analysis of the differences in utilization rates for various medical services between the self-employed and wage-earners.

Section 2 provides a brief review of previous literature. Section 3 outlines the empirical strategy and describes our data set, the 1996 wave of the Medical Expenditure Panel Survey (MEPS). The MEPS has rich information on individuals' utilization of a variety of medical services, including a set of important diagnostic tests. Section 4 discusses econometric issues and presents the results. The main finding is that even though the self-employed are less likely to have insurance than wage-earners, the gap in the utilization of health care services is generally fairly small. Indeed, for some important services, there is no substantial gap at all. In Section 5 we turn to the closely related question of whether the medical expenditures incurred by the self-employed substantially reduce their capacity to purchase other commodities, and find no evidence to support this concern. Further, in Section 6 we find that, to the extent that we are able

\footnotetext{
${ }^{3}$ Conventional economic analysis suggests other reasons why a subsidy might be worth considering, for example, horizontal equity. Nevertheless, utilization per se appears to be the primary issue in much of the
} 
to measure, the children of the self-employed are no less likely to have access to medical services than the children of wage-earners. Hence, concerns that the self-employed need insurance subsidies in order to increase their utilization of medical services, to maintain their standard of living, or to help their children obtain health care may be misplaced. Section 7 provides a summary and suggestions for future research.

\section{Previous Literature}

The determinants of health care utilization have been the subject of several studies. Kass, Weinick and Monheit [1999] used the MEPS data to examine differences in utilization rates by race. A noteworthy aspect of their study is that they moved beyond the conventional approach of considering only doctor visits or hospital admissions. Instead they studied a wide variety of health services, including diagnostic tests such as breast exams, which many medical practitioners view as being important for maintaining good health. Their analysis, however, was confined to comparisons of means by race. They did no multivariate analysis to take into account other variables that might affect utilization rates. Gilleskie [1997] studied utilization decisions in the context of worker absentee decisions, but only considered doctor visits. Currie and Gruber's [1995] careful examination of the effect of changes in Medicaid eligibility on medical care utilization looked only at doctor visits and hospitalizations and focused on the low-income part of the population. In the RAND Health Insurance Experiment, individuals were randomly assigned to health insurance plans with different co-payments and deductibles (Newhouse, et al. [1993]). The results suggested that the greater the cost sharing, the smaller the individual's health expenditures. Similarly, Hurd and McGarry [1997] found 
that, among the elderly, those who have the most insurance use the most health care services. None of these studies considered issues relating to self-employment.

In short, the papers in the existing empirical literature either look at a restrictive set of utilization measures or ignore the multivariate nature of the problem of explaining differential utilization rates across groups. What is more important given the public policy debate on subsidizing health insurance for the self-employed, none of them studies the links among insurance, utilization, and self-employment. ${ }^{4}$

Our focus has been on the literature analyzing the positive question of how insurance relates to utilization rather than the normative question of whether the government should subsidize insurance purchases in order to increase utilization. The issue is particularly cogent in the United States, where in general the government provides insurance only to certain low-income individuals (through Medicaid) and to the elderly (through Medicare). The normative literature has noted that adverse selection can lead to under-provision of health insurance in such a (primarily) private market. In this context, a tax subsidy to encourage purchases of health insurance can enhance efficiency. On the other hand, authors such as Feldstein [1995] have argued that adverse selection is not of major practical importance in the U.S. context, and that the tax subsidy leads to over-provision of health insurance. Determining the optimal government intervention in a private health insurance market is a complicated issue beyond the scope of this paper. We merely note that the answer to the normative question must ultimately depend, inter alia., on the positive question of how utilization of health care, and ultimately health status itself, are linked to insurance coverage. 


\section{$\underline{\text { 3. Data }}$}

\section{$\underline{3.1 \text { Description }}$}

Our basic goal is to see if the differences between the self-employed and wageearners in their insurance rates are associated with differences in their utilization of various medical services. We require information on individuals' utilization of various medical services and insurance coverage, along with a set of exogenous characteristics that might be expected to influence utilization and insurance decisions. We draw upon the Household Component of the 1996 Medical Expenditure Panel Survey (MEPS). The panel consists of approximately 22,000 respondents who comprise 9,500 families. The respondents were asked a series of questions relating to their demographic characteristics, insurance coverage, employment status, and medical care use. We exclude from the sample those with missing information on education and insurance status as well as individuals who were not employed. Further, we exclude any persons younger than 18 and older than $62 .^{5}$ Those under 18 are unlikely to have developed a strong attachment to the labor market, and the decisions of those over 62 are complicated by impending retirement. Further, about 95 percent of individuals over 65 are covered by Medicare. All of these exclusions left a group of 9552 individuals, of whom 1158 (12 percent) were self-employed. This corresponds fairly closely to other estimates of the self-employment rate in 1996 (U.S. Bureau of the Census [1998, p. 412]).

As noted in section 2, most previous studies of access have relied on a very

\footnotetext{
${ }^{4}$ In contrast, there is a substantial literature on how the implicit subsidy for health insurance in the tax code affects insurance coverage for the self-employed. See, for example, Gruber and Poterba [1994] and Marquis and Long [1995].
} 
limited set of utilization measures. An important strength of the MEPS is that in addition to insurance status, it contains information on a large variety of medical services, including not only conventional items such as doctor visits and hospital stays, but also visits to other kinds of practitioners like dentists and chiropractors. As well, it provides data on the utilization of some important diagnostic procedures, such as breast examinations and blood pressure tests. Somewhat arbitrarily, we divide the procedures into two groups. The first group, site-based services, consists of doctor visits, hospital admissions, hospital stays, chiropractor visits, optometrist visits, and alternative care. The second group, screening and preventative care services, consists of breast exams, physical exams, dentist visits, flu shots, mammograms, prostate exams, prescription medicine purchases, blood pressure checks, and cholesterol checks. ${ }^{6}$

Of course, utilization rates do not necessarily measure adequately the quality of services received. Two people who both visit the doctor during the year are not automatically receiving the same health care. For example, during a given visit, a physician might spend more time with an insured patient than an uninsured patient, or order more diagnostic tests for the former than the latter. In Section 5 below we examine this conjecture using data on expenditures per doctor visit. Another possible problem with studying utilization measures is that we ultimately care about the "output" health status rather than the health services "inputs" per se. This is a legitimate concern, and we have examined health outcomes in another paper (Perry and Rosen [2001]). However, access to health care is of independent interest, if for no other reason than it clearly drives

\footnotetext{
${ }^{5} \mathrm{We}$ lose 28 observations because of missing data on education, 3612 because of missing data on employment, 4 because of missing insurance data, and 10,034 from the exclusion of those over 62 .

${ }^{6}$ For several of these procedures (e.g. breast exam, cholesterol check, prostate exam) the MEPS provides the history of utilization. That is, we know if the individual had the procedure within the past year, within
} 
the public policy debate. Recall Congressman Dreir's statement that was quoted above:

"Accessibility is our key."

\subsection{A Preliminary Look at the Data}

Table 1 focuses on insurance coverage and rates of health care utilization by employment status. For each variable, column (1) shows the mean for the entire sample; column (2) the mean for the self-employed; and column (3) the mean for wage-earners. The fourth column displays the t-statistics associated with the hypothesis that the means of the relevant variables are equal.

The first row of the table shows rates of insurance for each group. It is based on a dichotomous variable in the MEPS file that takes a value of one if the individual has health insurance coverage and zero otherwise. Specifically, the variable equals one if the individual is covered under Medicare, Medicaid, CHAMPUS/CHAMPVA ${ }^{7}$, other public hospital/physician or private hospital/physician insurance. (An individual who receives spousal coverage is construed as being covered for purposes of defining this variable.) The results in the first row of the table indicate that the self-employed are substantially less likely than wage-earners to have any health insurance. Only 68 percent of the selfemployed in our sample have insurance compared with 81 percent of the wage-earners. From column (4), this difference is significant at all conventional levels, a finding consistent with tabulations from other data sets. ${ }^{8}$

\footnotetext{
the past two years, within the past 5 years, more than 5 years ago, or never had one. Since we only have insurance data from the past year, we focus exclusively on utilization within the past year.

${ }^{7}$ CHAMPUS is a health benefits program designed to provide medical coverage for the dependents of active duty military servicemen/women. CHAMPVA is intended for dependents and survivors of severely disabled veterans.

${ }^{8}$ See, for example, Holtz-Eakin, Penrod, and Rosen's [1996] tabulations from the SIPP data or Health Insurance Association of America [1999].
} 
A key question is whether the relative lack of insurance on the part of the selfemployed is associated with a commensurate lack of utilization of health services. The results in Table 1 are quite interesting in this respect. For some services (hospital admissions, hospital stays, cholesterol exams, dental checkups, mammograms, and optometrist visits), there are no statistically significant differences in utilization rates. Second, for other services, there are statistically significant differences, but the selfemployed have higher utilization rates (alternative care, prostate exams, chiropractor visits). In the cases where the utilization rates are statistically significantly lower for the self-employed, the question is whether or not the differences are large. "Large," of course, is in the eyes of the beholder. It strikes us that at least some of the differences are not substantial. For example, the probability of visiting a doctor is only 4.3 percentage points (or 6 percent) less. On the other hand, the probability of receiving a breast exam is 9.3 percentage points (or 31 percent) less.

In short, the tabulations in Table 1 suggest that despite their relatively low insurance rates, the self-employed are not necessarily less likely than their wage-earning counterparts to utilize a variety of health care services. Further, where the self-employed are statistically less likely to use services, the percentage differences are often not very large. ${ }^{9}$ That said, we should not make too much of the specific results in Table 1, because a variety of factors might influence utilization of health care services, and some of these could be correlated with self-employment status. Hence, while the results are suggestive, we now turn to a multivariate approach.

\footnotetext{
${ }^{9}$ We also did two-way comparisons of utilization rates by employment status and insurance status. For most services, the average utilization rates are less for the self-employed than for wage-earners, even when they have the same insurance status. This is consistent with the message of Table 1, that insurance cannot entirely "explain" the differences between wage-earners and the self-employed. However, this finding
} 


\section{Multivariate Analysis of Utilization Rates}

The preliminary calculations in Table 1 suggest that self-employed individuals' low propensity to have medical insurance does not necessarily translate into less utilization of medical services. But such univariate comparisons ignore the fact that variables other than employment status may affect utilization rates. An appropriate empirical model should allow the probability that an individual utilizes a given medical service to depend on his or her relevant personal characteristics as well as selfemployment status. We use the conventional probit model, which posits that the probability that individual $i$ utilizes some service is given by

$$
\operatorname{Prob}\left(U t i l_{i}>0\right)=\mathrm{F}\left[\beta \mathrm{X}_{i}+\delta S E_{i}\right]
$$

where $X_{i}$ is a vector of observable demographic characteristics, $S E_{i}$ is a dichotomous variable equal to one if the individual is self-employed and zero otherwise, and $F[$ ] is the cumulative normal distribution.

An important issue is what variables to include in the vector of demographic characteristics $X_{i}$. The MEPS contains fairly extensive demographic information. We attempted to select only those characteristics that were very likely to be exogenous to insurance and health care utilization decisions. Age is included because it affects the likelihood of needing health services - health problems tend to increase with age (Lakdawlka and Philipson [1998]). Also, certain procedures like mammograms and 
prostate exams become highly recommended only after certain ages are reached. We also include the square of age because previous research suggests that a quadratic function may be appropriate. ${ }^{10}$ Education can be expected to influence both individuals' physical condition and their capacity to pay for care (Taubman and Rosen [1982]); hence we include a set of dichotomous variables for educational attainment. On the basis of previous analyses, we also include a set of race/ethnicity dichotomous variables (Kass, Weinick, Monheit [1996]), a set of indicator variables for the region of the country in which the person lives (Skinner and Wennberg [1998], Cutler and Sheiner [1999]), ${ }^{11}$ a dichotomous variable for the individual's $\operatorname{sex}^{12}$, a dichotomous variable for marital status, and a continuous variable for family size--number of adults plus dependents (Taubman and Rosen [1982]). ${ }^{13}$

Our specification omits certain variables that have appeared as covariates in several previous studies of health care utilization. For example, Stabile [1998] and Ross and Mirowsky [2000] include on the right hand side of their utilization equations indicator variables for the individual's insurance status, self-assessed health, and the presence of any chronic health conditions. Ross and Mirowsky include income as well. Such variables might very well be endogenous, however. With respect to insurance, for example, Gruber [2000, p. 46] notes, "insurance coverage itself may be a function of health status, leading to endogeneity bias in estimates of the effects of insurance on

\footnotetext{
status).

${ }^{10} \mathrm{We}$ also entered age as a set of dichotomous variables instead of a quadratic, and it had no impact on our substantive results.

${ }^{11}$ The regional classifications correspond to those used by the Census Bureau.

${ }^{12}$ See Hagan, Simpson, and Gillis [1987] and Barber and Odean [2000] on differences in risk preferences by sex.

${ }^{13}$ However, one can imagine that marital status and family size may be endogenous to medical services utilization. We therefore estimated our models without these two variables. Doing so had no impact upon the basic results.
} 
health and on the utilization of medical care." In the same way, there is a substantial literature documenting the links between income and health status, but the direction of causality is not known. (See, for example, Deaton and Paxson [1999] and Ettner [1996].) To the extent that individuals' incomes are low because they are in poor health (and utilizing health care services intensively), then income is an endogenous variable and should be excluded from the reduced form. ${ }^{14}$ Using income in the context of comparisons between wage-earners and the self-employed is particularly problematic. Self-employment income may be measured incorrectly because individuals fail to take into account, among other things, the opportunity cost of the capital they have invested in their enterprises (Hamilton [2000]).

We try to include only exogenous variables on the right hand side of equation (4.1). While this makes it difficult to attach a structural interpretation to the results, it does increase the likelihood of obtaining consistent parameter estimates. ${ }^{15}$ As noted above, we control for a number of demographic variables. ${ }^{16}$ A relevant question in this context is whether there is unobservable heterogeneity with respect to the

\footnotetext{
${ }^{14}$ Nevertheless, as an experiment, we estimated our canonical model including income on the right hand side. We found that while income was positively related to insurance coverage and utilization, our substantive results did not change. Specifically, the self-employment effect on insurance coverage was still about the same magnitude and statistically significant $(-0.220$ with a standard error of 0.017$)$. The selfemployment differential on doctor visits was even smaller than in Table 3 (-0.0195 with a standard error of 0.00686 ), and for most of the other services, the self-employment differentials were about the same as in Tables 3 and 4 (e.g., the prostate exam differential was $-0.0558($ s.e. $=0.0143)$ and the cholesterol test differential was $-0.0743($ s.e. $=0.0158)$ ). In the same spirit, we also augmented the equation with dichotomous variables for the industry in which the individual worked. This, too, left our substantive results unchanged.

${ }^{15}$ Despite the likely endogeneity of insurance status, for the sake of completeness, we estimated the basic equation including the insurance dichotomous variable and its interaction with the self-employment indicator on the right hand side. As expected, for most health care services, insurance increases the probability has a positive and significant coefficient. Importantly, the results with respect to the impact of self-employment are very similar to those reported below.

${ }^{16}$ In our sample, on average the self-employed are more likely to be white, male, and married with a spouse present. Further, the self-employed tend to be older (5.2 years) on average than wage-earners. These findings on demographic differences between self-employed and wage-earning individuals generally echo
} 
utilization of health care services. Do the self-employed and wage-earners differ systematically in their underlying demands in a way that cannot be captured by our covariates? In particular, might there be unobservable variables that drive both the demand for health care services and the propensity to become self-employed? Suppose, for example, that self-employment requires a lot of energy and vigor. Healthy people (who tend not to demand many medical services) will therefore tend to enter selfemployment, ceteris paribus. The self-employed, then, utilize fewer health services simply because they are healthier than wage-earners. Put another way, if there is some underlying relationship between health and employment status, it may muddy the interpretation of our results.

Previous research suggests that this is probably not much of a problem. HoltzEakin, Penrod, and Rosen [1996] employed both the Survey of Income and Program Participation (SIPP) and the Panel Study of Income Dynamics (PSID) data to examine transitions from wage-earning to self-employment. Both data sets indicate that in a given year, those wage-earners who become self-employed in the future are not statistically different in their health status or health care utilization from the ones who remain wageearners. ${ }^{17}$ This result is confirmed by Perry and Rosen [2001], who analyze transitions from wage-earning to self-employment and vice versa in the MEPS data. While these findings cannot definitively exclude the possibility of unobservable heterogeneity, they

\footnotetext{
those of previous research; see, e.g., Fairlie and Meyer [1999]. Summary statistics are available upon request to the authors.

${ }^{17}$ In the SIPP data, the health measures were combined days in bed during the last 4 months and a selfreported health status variable. The utilization measures were combined nights in a hospital in the last 4 (and 12) months and the combined number of doctor visits in the last 4 (and 12) months. In the PSID the health measures were hours of work lost due to illness and a self-reported health variable. The utilization measure was number of nights in the hospital during the year. These results are cited in Holtz-Eakin, Penrod and Rosen [1996]; more detailed documentation is reported in the National Bureau of Economic Research Working Paper with the same title, number 4880 (October 1994).
} 
certainly provide no evidence that people who select into self-employment are systematically different with respect to health-related attributes. ${ }^{18}$

\subsection{Basic Results.}

Following the same tack as our discussion of the unadjusted differences between self-employed and wage-earning individuals surrounding Table 1, our first multivariate analysis uses an equation analogous to (4.1) to examine the probability of being insured; we then turn to the various utilization measures.

Insurance coverage. The results are presented in column (1) of Table 2. The figures are the marginal effects of each of the variables on the probability of having insurance coverage. Importantly, the coefficient on the self-employed variable is both negative and statistically significant. To put the coefficient of -0.203 in perspective, note that 80.9 percent of the wage-earners have insurance. Hence, the self-employed are 25.1 percent less likely to be insured even after controlling for other variables such as education and race.

Utilization. With the results on insurance coverage in hand, we now turn to the analysis of the various utilization measures. Column 2 of Table 2 reports the results for the probability of a doctor visit in 1996 . The coefficient on the self-employment variable is negative $(-.0585)$ and significant $(t=-3.58)$. Given that the probability for a wageearner visiting the doctor is 0.62 , this implies that the self-employed are about 9.3 percent less likely to visit the doctor than wage-earners. As before, we face the problem of determining whether this figure is "large." While nontrivial, it is considerably less than

\footnotetext{
${ }^{18}$ These considerations suggest that to obtain a consistent estimate of the impact of insurance on utilization, one could use instrumental variables, with self-employment status as an instrument for insurance. Such a
} 
one might expect given the differential in insurance probabilities, especially in light of Hurd and McGarry's [1997, p. 131] observation that, in general, "the empirical literature does demonstrate a strong correlation between insurance coverage and service use."

As stressed above, we are interested in a variety of medical services, not just doctor visits, so we next re-estimate the model for each of a series of utilization measures. These results are displayed in columns (3) through (7) of Table 2. Taken in conjunction with the insurance results in column (1), the coefficients on the selfemployment variables in (3) through (7) suggest several related conclusions. First, for some services such as hospital admissions, hospital stays and optometrist visits, the differences in utilization probabilities between wage-earners and the self-employed are not statistically significant at conventional levels. The absence of any differences for optometrist visits comes as no surprise because they are generally not covered by insurance, but this is not the case for hospital admissions and hospital stays. Second, for two categories, visits to chiropractors and alternative care, the self-employed have higher utilization rates. We conjecture that relative price effects are at work here. To the extent that services in these categories are not covered by insurance for a particular individual, they are expensive relative to other medical services that are. In effect, the prices of chiropractors and alternative care relative to conventional medical services are lower for those without insurance. Because the self-employed are less likely to be insured, then, their demand is higher than that of their wage-earning counterparts. Tastes may play a role here as well. The benefits from alternative medicine--acupuncture, massage, biofeedback training, hypnosis, etc.--are far less well documented than those from conventional therapies. Schumpeterian tradition views the self-employed as being less 
risk-averse and more adventuresome than wage-earners; hence, they may find such treatments more attractive.

Table 3 presents the probit results for screening and preventative care utilization. In general, the self-employed are less likely to utilize such services than wage-earners. For three services (flu shots, mammograms, and prostate exams), the percentage differences are quite large; the others are modest in magnitude in light of the insurance differential.

An important message from Tables 2 and 3 is that the utilization differentials vary across services. A natural question is whether the services with particularly large differentials are in some sense "important." Should there be public policy concern over the fact that the self-employed are substantially less likely than wage-earners to consume these particular services? The three services with the largest differentials in percentage terms are mammograms, prostate exams, and flu shots. The relative infrequency of mammograms and prostate exams seems a serious issue. It may be, however, that the figures in Table 3 overstate the differential for these two tests. They are generally recommended only for people over the age of 40 . When we re-estimated the relevant probit equations including only individuals over 40 , we found that, within this age group, self-employed women are 14 percent less likely to have mammograms than their wageearning counterparts, and self-employed men are 17 percent less likely to have prostate exams than their wage-earning counterparts. These figures are substantially smaller than those in Table 3. In any case, to the extent that there are substantial differentials in the utilization of certain tests, it is not clear that the solution is a special deduction for health insurance in the tax code. Targeted policies such as price subsidies might be more 
appropriate.

\section{$\underline{4.3 \text { Alternative Specifications }}$}

We subjected our model to a variety of tests to see whether our substantive results were sensitive to changes in specification.

Males versus females. The canonical specification in Tables 3 and 4 imposes the constraint that men and women differ in their insurance coverage and utilization rates only by an intercept. However, medical conditions and risk aversion differ by sex, so the process governing the relationships among insurance, utilization, and employment status may be different as well. We therefore re-estimated the basic specification separately by sex. The results, available upon request, suggest that, in general, there are no substantial differences by sex in the magnitudes of the self-employment effects on the utilization of the various services.

Hours of work. It is well documented that the compensation packages of part-time workers are less likely than those of full-time workers to include benefits such as medical insurance (Campling [1987], Committee on Ways and Means [1998, p. 1107]). At the same time, hours of work might be correlated with self-employment status. In fact, the correlation in our data is 0.106 . Hence, our estimates of the effects of self-employment on insurance coverage and utilization rates might be biased because of the failure to take into account differences in hours worked. We therefore augmented our basic specifications from Tables 2 and 3 with a set of dichotomous variables for hours worked 
per week. ${ }^{19}$ Of course, hours of work might itself be endogenous--people who use health care intensively may be ill and work fewer hours, ceteris paribus. This is why we chose not to include it in our canonical model.

In results available upon request, we found that the inclusion of hours of work has barely any impact on the self-employment effect. The most substantial changes occurred in the estimates for breast exams and cholesterol checks. Interestingly, in those cases, the coefficients on the self-employment variable become less negative once indicators for hours of work are included on the right hand side. The changes are on the order of 2 percentage points. Thus, the inclusion of hours of work in the model reduces the differences in utilization rates associated with self-employment.

Organizational form. So far, we have assumed that the self-employed are a homogeneous group with respect to the institutional environments in which they function. However, self-employed individuals operate in different organizational forms--sole proprietorships, partnerships, and corporations--and the probability of being insured could vary with organizational form. In particular, those who are incorporated might be more likely to have insurance for two reasons. First, their expenditures for health insurance are fully deductible; for members of partnerships and sole proprietors, they are not. Second, to the extent that corporate enterprises have more employees, the owners can purchase insurance at advantageous group rates. ${ }^{20}$ Under these assumptions, we can use the MEPS data on organizational form to examine further whether differences in insurance coverage drive differences in utilization. Specifically, to the extent that

\footnotetext{
${ }^{19}$ There are three indicator variables. The first is equal to one if the individual works between 20 and 35 hours per week; the second between 35 and 45 hours; and the third more than 45 hours. The omitted category is less than 20 hours per week.

${ }^{20}$ See Thomasson [2000] on the advantages of group coverage.
} 
insurance is an important factor, one would expect incorporated self-employed individuals to utilize more medical services than their unincorporated counterparts, ceteris paribus.

To investigate this possibility, we augment our basic specification with a set of interactions between organizational form and self-employment status:

$$
\operatorname{Prob}\left(U t i l_{i}>0\right)=\mathrm{F}\left[\beta X_{i}+\delta S E_{i}+\gamma S E_{i}{ }^{*} I N C O R P_{i}+\lambda S E_{i}{ }^{*} P R O P_{i}\right],
$$

where $I N C O R P_{i}$ is a dichotomous variable equal to one if an individual is incorporated, $P R O P_{i}$ equals one if the individual is organized as a sole proprietor, and the other variables are as defined above. This augmented specification allows for differential effects by organizational form-- $\delta$ is the effect if the self-employed individual is in a partnership, $\delta+\gamma$ if incorporated, and $\delta+\lambda$ if a sole proprietor (all relative to being a wageearner).

Table 4 reports the estimates of the key parameters of equation (4.2), $\delta, \gamma$, and $\lambda$. The first row shows the results for the probability of having insurance. According to the point estimate in column (1), a self-employed individual in a partnership is 25 percentage points less likely to have insurance coverage than a wage-earner. From columns (1) and (2), an incorporated individual is only 15 percentage points $(=-.25+.10)$ less likely to have insurance, and from columns (1) and (3), a sole proprietor is 24.2 percentage points $(=-.25+.008)$ less likely, essentially the same figure as for a partner. Column (4) is the p-value of a chi-square test of the hypothesis that the effect of self-employment is zero; it is rejected at all conventional levels. Column (5) provides the p-value of the test of the 
hypothesis that the total effect for incorporated individuals is zero; and column (6)

presents the result for sole proprietors. In both cases, one can easily reject the hypothesis that the effects are zero. The key result is that the data are consistent with our conjecture above: relative to their counterparts in partnerships and sole proprietorships, incorporated individuals are more likely to have insurance (although still less likely than wageearners).

Is this differential in insurance coverage associated with differential utilization of medical services for incorporated individuals? As we move down column (2) of the table, the answer is generally no. Except for blood pressure checks and flu shots, the interaction terms are statistically insignificant. Further, according to the figures in column (5), for about half the procedures, the incorporated self-employed have about the same utilization rates as wage-earners, despite the fact that their coverage rates are 15 percentage points less.

An implicit assumption behind this discussion is that operating as a corporation is primarily an indicator for insurance status. It could reasonably be argued, however, that it is mainly an indicator for income - self-employed individuals who have gotten to the stage where it is worthwhile to incorporate have higher incomes than partners and sole proprietors, ceteris paribus. Note that we would expect income and insurance to work in the same direction as far as their effects on utilization of medical services- - both would tend to have a positive effect. While this clouds the meaning of statistically significant interaction terms in column (2), it does not substantially affect our interpretation of insignificant effects - a zero is entirely consistent with no insurance effect.

Intensity of utilization: doctor visits. In general, the MEPS tells us only whether 
or not an individual utilized a given kind of health care, not how intensively. This accounts for our focus on the probabilities of using various medical services. However, information on the number of times that the individual went to the doctor is available. We take advantage of these data to estimate how the self-employed differ from wageearners with respect to the number of doctor visits. The idea is to see if our story on differences in the use of medical services changes when we allow the intensity of utilization to vary across individuals.

We employed the same explanatory variables as in our basic model, equation (4.1). A complication is introduced by the fact that a substantial number of observations are at zero hours (see Table 1). We therefore use a Tobit estimator. The coefficient on the self-employment variable is -0.69 with a standard error of 0.25 - the self-employed pay fewer visits to their doctors, ceteris paribus. ${ }^{21}$ To assess the quantitative significance of the coefficient, we began by computing the expected number of visits assuming $S E$ is equal to zero and setting all the other variables at their means. We then repeated the exercise assuming $S E$ is one. This exercise suggested that the impact of being selfemployed is .03 fewer visits, or 1.09 percent. ${ }^{22}$ Thus, when we take advantage of the extra information on intensity of utilization of doctor visits, it reinforces the results from Table 2 on the dichotomous choice - the differential between the self-employed and wage-earners with respect to doctor visits is not very large, particularly in light of the differential in insurance coverage.

\footnotetext{
${ }^{21}$ The full set of Tobit results is available upon request.

${ }^{22}$ The expectations were computed according to the standard formula $\mathrm{E}(\mathrm{Y})=\mathrm{F}\left(\beta^{*} \mathrm{X} / \sigma\right) * \beta^{*} \mathrm{X}+\sigma^{*} \mathrm{f}\left(\beta^{*} \mathrm{X} / \sigma\right)$, where $\sigma$ is the standard error associated with the Tobit index, $\mathrm{F}()$ is the cumulative normal distribution, and $\mathrm{f}(\mathrm{)}$ is the standard normal distribution (Maddala [1983, p. 159]).
} 


\section{Health Care Expenditures}

So far our focus has been on differential utilization rates. This reflects the dominant question in the public policy debate--are the relatively low rates of insurance among the self-employed associated with less access to health care? The MEPS data also contain information about expenditures on health care, both out-of-pocket and total. Analysis of these data can cast further light on the question of whether a public policy response is required to the relatively low rates of health insurance among the selfemployed.

To begin, we note that the debate over health care sometimes loses sight of the key function of insurance--to spread consumption over different states of the world. Hence, even if the self-employed have access to health care, we cannot necessarily be sanguine about their relative lack of insurance. We need to know if paying for health care causes serious reductions in their standard of living.

The MEPS data contain information about family out-of-pocket expenditures on health care (including expenses on insurance and medical services). To examine whether the self-employed's lack of insurance forces large reductions in their living standards, we began by analyzing how these expenditures vary with employment status. Specifically, we estimated a model in which individual out-of-pocket expenditures depend upon the same variables as the basic utilization equations of Table 2. Because a substantial number of individuals have zero out-of-pocket health care expenditures (21.7 percent), we again use the Tobit statistical model.

The coefficient on the self-employment variable is 141 with a standard error of

28.3. This result confirms what intuition might suggest--the self-employed have more 
out-of-pocket health care costs than wage-earners, ceteris paribus. However, from a quantitative standpoint, the difference is not very large--using the same computational method as in Section 4.2, the expected difference in out-of-pocket expenditures is only \$84.42. A similar exercise indicates that total expenditures on health care are smaller for the self-employed (by \$228), again as one might expect.

In this context, it is perhaps more informative to ask how out-of-pocket expenditures relative to income depend on employment status. We therefore re-estimated the model with expenditures as a fraction of income on the left-hand side, again using a Tobit model. ${ }^{23}$ The coefficient on the self-employment variable is both positive $(0.00748)$ and significant (s.e. $=0.00194)$, indicating a higher fraction of out-of-pocket costs for the self-employed. However, again proceeding as in Section 4.2, our results imply that, on average, the self-employed devote only 0.4 percent more of their incomes to out-of-pocket medical expenditures than wage-earners.

Because the purpose of insurance is to smooth consumption, if a substantial number of the self-employed experience major health expenditures relative to their incomes, we might be concerned even if, on average, the ratios of out-of-pocket expenditures to income are about the same. It is therefore useful to know more about the distribution of the ratio of out-of-pocket costs to income than its mean. Hence, we computed the ratio at various percentiles. Within the sample of wage-earners, the ratio of out-of-pocket costs to income at the 75 th percentile is 0.0137 ; for the self-employed it is 0.0160 . At the 90th percentile, the figures are 0.0347 and 0.0479 for wage-earners and the self-employed, respectively. The distributions of the level of out-of -pocket 
expenditures are qualitatively similar. At the 75 th percentile, expenditures are $\$ 454$ and $\$ 335$ for the self-employed and wage-earners, respectively. At the 90th percentile, the comparable figures are $\$ 1,877$ and $\$ 1,226$. It is hard to imagine that such differences are sufficient to merit public policy concern.

Another problem in the interpretation of our results on utilization is that they do not take into account possible differences in the quality of services. For example, we showed in Table 2 that the self-employed were only about 9 percent less likely to visit the doctor than wage-earners. But what if the quality of their visits was lower because they lacked insurance? In the absence of insurance, perhaps the self-employed visit less experienced physicians who charge lower fees. Or perhaps a given physician demands a lower fee from an uninsured self-employed patient, but then spends less time with him or her.

The MEPS provides no direct way to investigate this issue. However, as a very rough measure for quality, we can compare total expenditures (i.e., out-of-pocket plus insurance) per doctor visit for wage-earners and the self-employed. Given that a "doctor visit" is far from a homogeneous commodity ${ }^{24}$, it is not clear how much one can learn from such an exercise. Without making too much of it, therefore, we merely note that, conditional on making at least one visit to the doctor, mean expenditures per visit are $\$ 625.04$ for wage-earners and $\$ 450.69$ for the self-employed, a difference that is not statistically significant at conventional levels $(t=1.160)$. In this context, recall from Table 3 that, for a variety of diagnostic tests, there are not substantial differences in

\footnotetext{
${ }^{23}$ For families with implausibly low incomes, the ratio of expenditures to income may be very high, possibly skewing the results. Hence, for this exercise, we exclude observations for which income is less than $\$ 5,000$. This reduced the sample size by 601 .
} 
utilization rates between wage-earners and the self-employed. To the extent that such tests themselves can be viewed as indicators of the quality of health care, the Table 3 findings are consistent with insubstantial differences in quality between the two groups.

\section{Children's Issues}

In recent years, much of the debate over health insurance has focused on the needs of children. In the fall of 2000 , for example, the New York Times noted that "Health care for children has become a major issue in the presidential campaign" [Pear, 2000, p. A1]. Even if health services utilization is not a problem for the self-employed, one still might make a case for insurance subsidies if this promoted access to health care for their children. The MEPS data contain a set of questions relating to preventative care for children as well as information on their doctor and hospital visits. ${ }^{25}$ In this section we examine how children's medical services utilization depends on their parents' employment status.

Because the relevant question is the impact on the child's utilization of the parents' self-employment status, we create a dichotomous variable, PARENTSE, which is equal to one if both parents are self-employed or only one parent works and he/she is selfemployed, and equal to zero otherwise. Following the same strategy as before, we begin by asking how the probability of the child's having health insurance varies with PARENTSE, ceteris paribus. We estimate a probit model in which the probability of insurance coverage depends upon the child's age, race, sex, and region as well as

\footnotetext{
${ }^{24}$ See Eichner, McClellan and Wise [1999] for a careful analysis of sources of differences in health care expenditures among employer-provided health plans.

${ }^{25}$ The preventative care information is for children seven or under, and the doctor visit information is for children 17 and under.
} 
PARENTSE. The coefficient on the self-employment variable is 0.040 with a standard error of 0.0322 -- children of the self-employed are about as likely to have insurance coverage as wage-earners' children. In light of the insurance gap between self-employed and wage-earning adults (see Table 2), this result is striking. It suggests that parents place a premium on having their children insured. There is certainly anecdotal evidence to this effect. Several months ago, the New York Times interviewed a father who continued to purchase health insurance for his children even after a very substantial increase in the premium. The father observed, "these are my kids we're talking about here. You never know what might happen...I wouldn't dream of them being without insurance" (Verhovek [2000, p. A1]).

In short, whatever problems the self-employed have in getting insurance for themselves do not seem to stand in the way of their obtaining insurance for their children. With this information in hand, the rest of the analysis is somewhat anti-climactic. We found that, ceteris paribus, the children of the self-employed are about as likely to visit the doctor or be admitted to the hospital as the children of wage-earners, are more likely to receive hepatitis vaccinations, and are about as likely to be vaccinated for measles/mumps/rubella. (Detailed results are available upon request.) In short, analysis of this admittedly limited set of children's utilization measures suggests that a child-based justification for an insurance subsidy for the self-employed is implausible.

\section{Conclusion}

Using data from the 1996 Medical Expenditure Panel Survey, we have analyzed differences between the self-employed and wage-earners with respect to insurance 
coverage and utilization of a variety of health care services. Our results suggest that for the self-employed, the link between insurance and utilization of health care services is weaker than some have suggested. For a number of medical care services, the selfemployed had the same utilization rates as wage-earners, despite the fact that they were substantially less likely to be insured. In most cases where the self-employed did utilize services less, the differences were not major. These findings were robust to a number of reasonable changes in the specification of our statistical model, and are particularly striking against the backdrop of a literature that, in general, finds strong correlations between insurance coverage and utilization of health care services (Hurd and McGarry [1997, p. 131]).

The self-employed thus appear to be able to finance access to health care from sources other than insurance. Perhaps the source is their own wealth, or perhaps they have better access to borrowing than wage-earners. ${ }^{26}$ In any case, to the extent that the goal of public policy is to increase the utilization of health care services among the selfemployed, providing them with health insurance subsidies may not be an efficacious measure. That said, there are reasons other than increasing utilization that might lead one to favor a subsidy. For example, to the extent that other parties are incurring the costs of treating the self-employed, there may be an efficiency rationale for inducing them to buy insurance (Coate [1995]). Another possible justification for a subsidy is horizontal equity--health insurance purchases of wage-earners and the self-employed should be treated in the same way (although to the extent that differences in the taxation of health insurance are capitalized into the returns to self-employment, this rationale is 
less compelling).

Of course, as Fuchs [1998], Gruber [2000], and others have observed, despite the focus of the public policy debate on insurance coverage and utilization rates, what we ultimately care about are health outcomes. The extent to which medical care has a positive effect on health is not clear. According to some studies, access to health care accounts for only a relatively small part of health, and more important determinants are genetics, environment, and health behaviors (Institute for the Future [2000, p. 23]). Consistent with this notion, Meara [1998] shows that access to health care is less important than maternal behaviors when it comes to explaining low birth weights, and Skinner et al. [2001] document that at a given point in time, variation in health care intensity appears not to improve survival probabilities among the elderly. An important question for future research is whether the large differences in their propensities to be insured lead to substantial differences in health status between wage-earners and the selfemployed. $^{27}$

\footnotetext{
${ }^{26}$ Recent press reports indicate that self-employed individuals are particularly likely to take advantage of "buyers' clubs" for health care services, which offer below-market prices on doctor visits, medical tests, and so on (Freudenheim, [2000, p. A1]). However, there are no data on the importance of this phenomenon.

${ }^{27}$ For some results along these lines, see Perry and Rosen [2001].
} 


\section{REFERENCES}

Barber, Brad M. and Terrance Odean, "Boys will be Boys: Gender, Overconfidence, and Common Stock Investment," Working Paper, University of California, Davis, February 2000.

Campling, R.F., "Employee Benefits and the Part-Time Worker," Working Paper, Queen's at Kingston - School of Industrial Relations, 1987.

Coate, Stephen, "Altruism, the Samaritan's Dilemma, and Government Transfer Policy," American Economic Review 85, March 1995, pp. 46-57.

Committee on Ways and Means, U.S. House of Representatives, 1998 Green Book, U. S. Government Printing Office: Washington, DC, 1998.

Currie, Janet and Jonathan Gruber, "Health Insurance Eligibility, Utilization of Medical Care, and Child Health," National Bureau of Economic Research, Working Paper No. 5052, March 1995.

Cutler, David and Louise Sheiner, "The Geography of Medicare," American Economic Review, May 1999, pp. 228-233.

Deaton, Angus and Christina Paxson, "Mortality, Education, Income and Inequality among American Cohorts," Working Paper, Research Program in Development Studies: Princeton University, June 1999.

Eichner, Matthew, Mark McClellan, and David A. Wise, "The Sources of Cost Difference in Health Insurance Plans: A Decomposition Analysis," National Bureau of Economic Research, Working Paper 7443, December 1999.

Ettner, Susan L., "New Evidence on the Relationship Betwen Income and Health," Journal of Health Economics 15, 1996, pp. 67-85.

Fairlie, Robert W. and Bruce D. Meyer, "Trends in Self-Employment Among White and Black Men: 1910-1990," National Bureau of Economic Research Working Paper 7182, June 1999.

Feldstein, Martin, "The Economics of Health Care: What Have We Learned? What Have I Learned?” National Bureau of Economic Research, Working Paper, February 1995.

Freudenheim, Milt, "'Buyers' Clubs for Medical Services Crop Up," New York Times, August 25, 2000, p. A1. 
Fuchs, Victor, "Health, Government, and Irving Fisher," National Bureau of Economic Research, Working Paper 6710, August 1998.

Gilleskie, Donna, "A Dynamic Stochastic Model of Medical Care Use and Work Absence," Econometrica, Vol. 66, No. 1, January 1998, pp. 1-46.

Gruber, Jonathan, "Medicaid," National Bureau of Economic Research, Working Paper 7829, August 2000.

Gruber, Jonathan and James M. Poterba, "Tax Incentives and the Decision to Purchase Health Insurance: Evidence from the Self-Employed," Quarterly Journal of Economics 104, August 1994, pp. 701-733.

Hagan, John, John Simpson, and A.R. Gillis, "Class in the Household: A Power Control Theory of Gender and Delinquency," American Journal of Sociology 92, no. 4, January 1987, pp. 788-816.

Hamilton, Barton H., "Does Entrepreneurship Pay? An Empirical Analysis of the Returns to Self-Employment," Journal of Political Economy 3, June 2000, pp. 604-631.

Health Insurance Association of America, Source Book of Health Insurance Data, 19992000, Washington D.C., 2000.

Holtz-Eakin, Douglas, John Penrod and Harvey S. Rosen, "Health Insurance and the Supply of the Entrepreneurs," Journal of Public Economics 62, 1996, pp. 209-235.

Hurd, Michael D. and Kathleen McGarry, "Medical Insurance and the Use of Health Care Services by the Elderly," Journal of Health Economics 16, 1997, pp. 129-154.

Institute for the Future, Health and Health Care 2010-The Forecast, The Challenge, Jossey-Bass Publishers: San Francisco, 2000.

Kass, B.L., Weinick R.M., Monheit A.C., "Racial and Ethnic Differences in Health, 1996," Agency for Health Care Policy and Research, 1999.

Lakdawalla, Darius and Tomas Philipson,"The Rise in Old Age Longevity and the Market for Long-Term Care," National Bureau of Economic Research, Working Paper 6547, May 1998.

Lueck, Sarah, "U.S. Sees Rise in the Number of Uninsured," Wall Street Journal, October 4, 1999, p. B4.

Maddala, G.S., Limited-Dependent and Qualitative Variables in Econometrics, Oxford University Press: New York, 1983. 
Marquis, M. and S. Long, "Worker Demand for Health Insurance in Non-group Market," Journal of Health Economics, Vol. 14, pp. 47-63, 1995.

Meara, Ellen, "Why is Health Related to Socioeconomic Status?" Working Paper, Harvard University, November 1998.

Newhouse, Joseph. Free for All? Lessons from the RAND Health Insurance Experiment, Santa Monica, CA: RAND, 1993.

Pear, Robert, "Insurers Ask Government to Extend Health Plans," New York Times, May 23, 1999, p. 16.

Pear, Robert, "40 States Forfeit Health Care Funds for Poor Children," New York Times, September 24, 2000, p. A1.

Perry, Craig W. and Harvey S. Rosen, "The Self-Employed Are Less Likely to Have Health Insurance than Wage-Earners. So What?" National Bureau of Economic Research, Working Paper 8316, June 2001.

Ross, Catherine E. and John Mirowsky, "Does Medical Insurance Contribute to Socioeconomic Differentials in Health?" The Milbank Quarterly 78, no. 2, 2000, pp. 291321.

Skinner, Jonathan and John Wennberg, "How Much is Enough? Efficiency and Medicare Spending in the Last Six Months of Life," National Bureau of Economic Research, Working Paper 6513, April 1998.

Skinner, Jonathan, Elliott S. Fisher and John E. Wennberg, "The Efficiency of Medicare," National Bureau of Economic Rsearch, Working Paper 8395, July 2001.

Stabile, Mark, "Private Insurance Subsidies and Public Health Care Markets: Evidence from Canada," Department of Economics: University of Toronto, 1999.

Taubman, Paul and Sherwin Rosen, "Healthiness, Education, and Marital Status," National Bureau of Economic Research, Working Paper 611, August 1982.

Thomasson, Melissa A., "The Importance of Group Coverage: How Tax Policy Shaped U.S. Health Insurance," National Bureau of Economic Research, Working Paper 7543, February 2000.

U.S. Bureau of the Census, Statistical Abstract of the United States: 1998 (118 $8^{\text {th }}$ Edition), Washington, DC, 1998.

Verhovek, Sam Howe, "Frustration Grows with Cost of Health Insurance," New York Times, September 18, 2000, p. A1. 
Table $1^{*}$

Summary Statistics: Insurance and Utilization Rates of Health Care Services

(1)

Entire Sample Self-Employed Wage-Earners
Test Statistic of Difference in Means Between

$(.470)$

.585

$(.493)$

.0423

$(.201)$

.0440

(.205)

.0550

(.228)

.0604

(.238)

.0349

(.184)

Visits

(.191)

.0420

(.200)

.0458

(.209)

.0412

(.199)

Alternative Care

.0652

$(.247)$

.100

(.300)

.0604

(.238)

Blood Pressure

.713

Exam

(.452)

Cholesterol

Exam

.363

(.481)

Breast Exam

.290

(.454)

Physical Exam

.404

(.491)

Dentist Checkup

.432

(.495)

Flu Shot

.166

(.372)
.662

(.473)

.355

(.479)

.208

(.406)

.358

(.480)

.440

(.497)

.142

(.349)
.720

(.449)

.364

(.481)

.301

(.459)

.410

(.492)

.430

(.495)

.169

(.375)
(2) and (3)

$-10.2$

(4)

(3)

$-2.79$

$-1.79$

$-1.56$

4.27

.725

5.15

$-4.08$

$-0.623$

$-6.57$

$-3.35$

0.643

$-2.33$ 
Table 1 - continued

(1)

\section{Entire Sample Self-Employed Wage-Earners}

$\begin{array}{ll}\text { Mammogram } & .107 \\ & (.309)\end{array}$

Prostate Exam $\quad .104$

$(.305)$

Prescription

Medicine

Purchase
(2)

(3)

(4)

Test Statistic of Difference in means between (2) and (3)

$-1.30$

(.311)
.0994

$(.299)$

.604

$(.489)$

3.70

$(.342)$

.560

(.49)

* Each entry in columns (1), (2), and (3) shows the proportion of the relevant group that utilized each health care service within the last year. Figures in parenthesis are standard errors. The first entry in each column shows the proportion of individuals who were covered by health insurance. Means for breast exams, prostate exams, and mammograms are taken only over the appropriate gender group. Column (4) shows t-tests on the differences in the means in columns (2) and (3). 


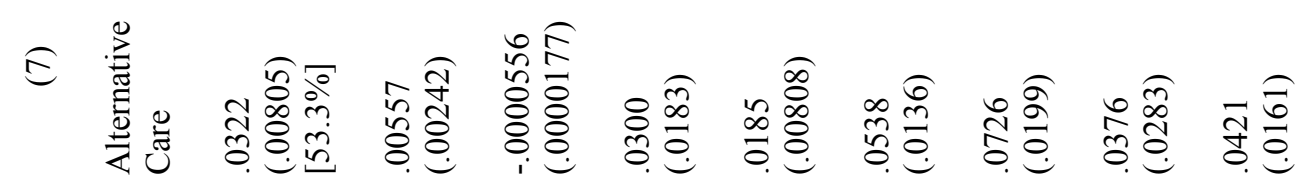

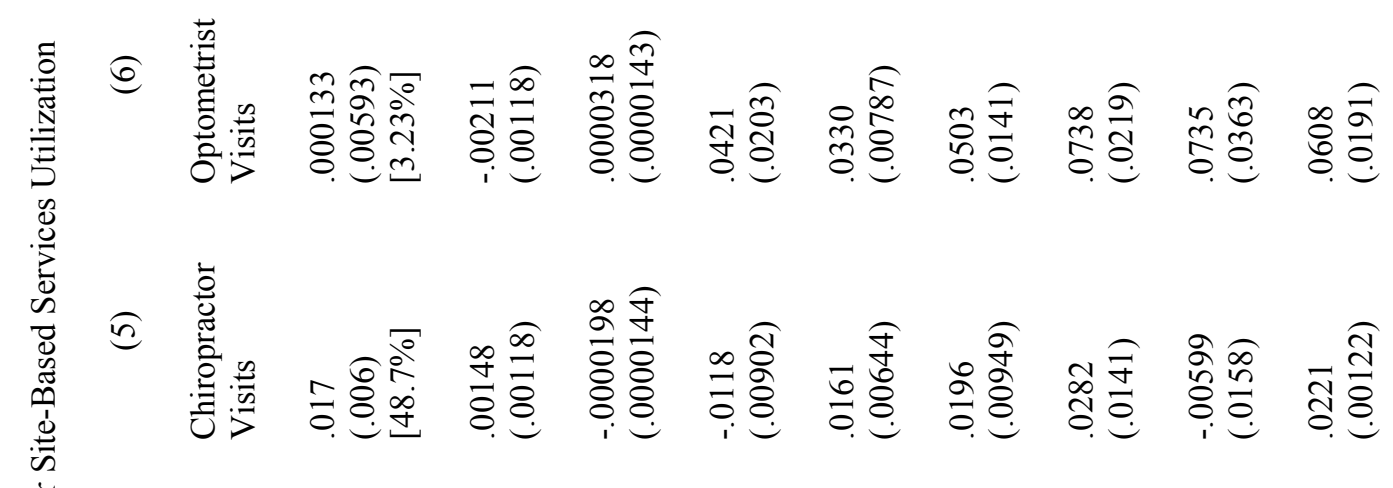

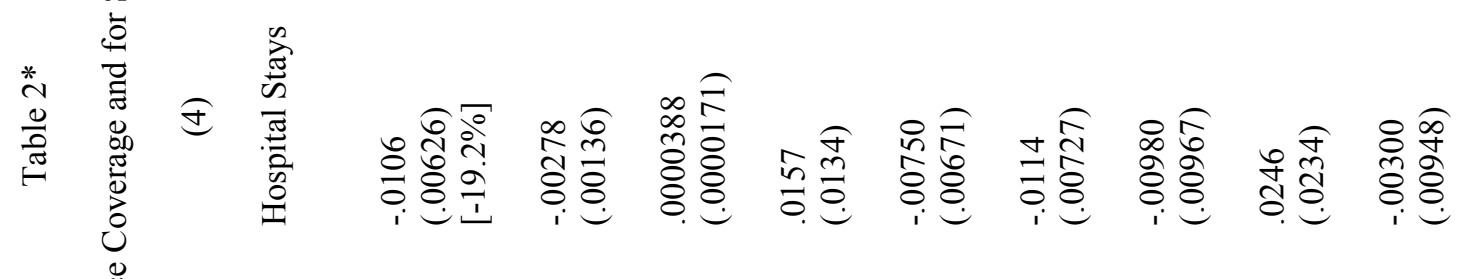

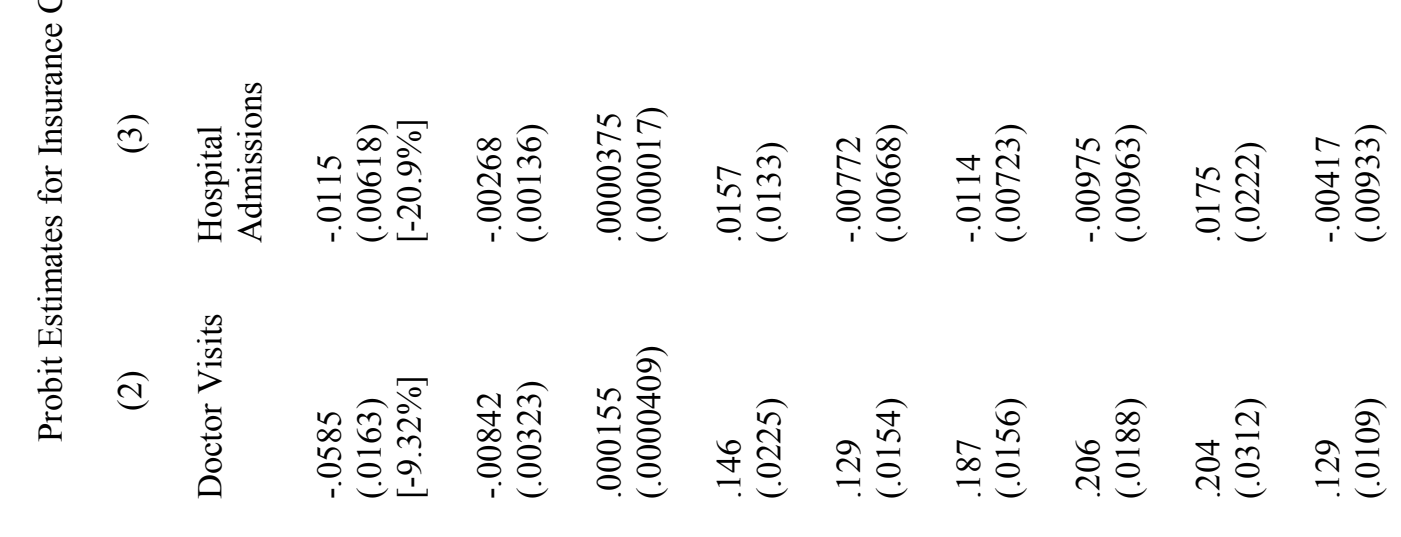

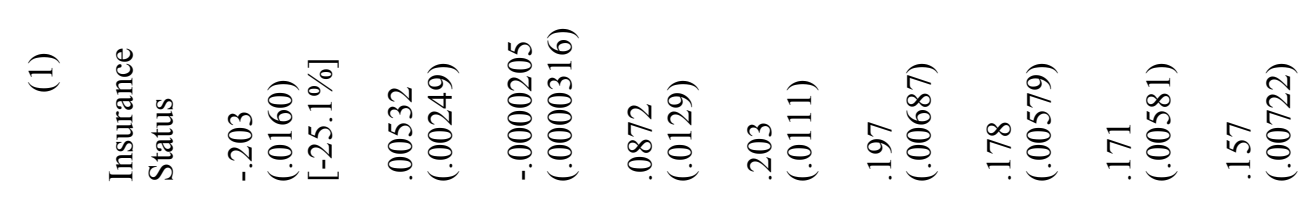

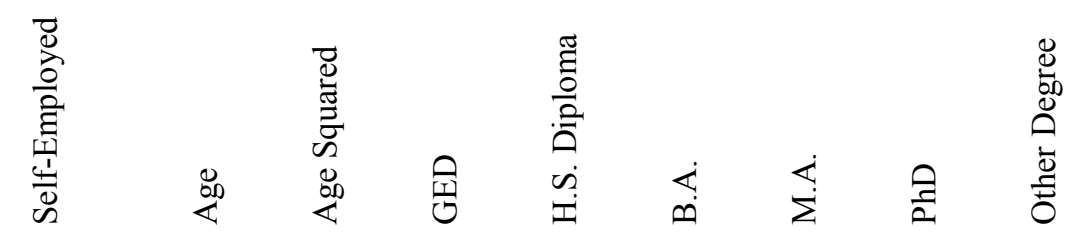




$$
\begin{aligned}
& \text { อใด }
\end{aligned}
$$

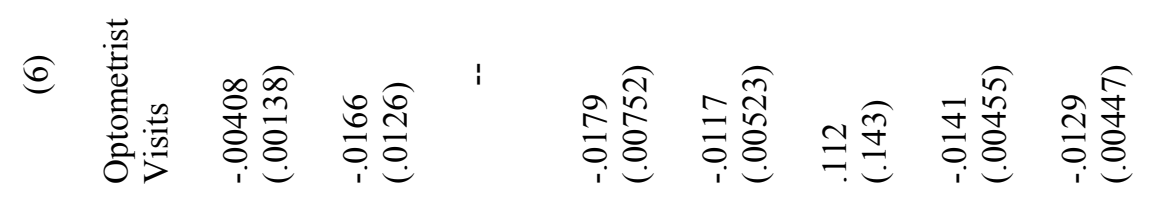

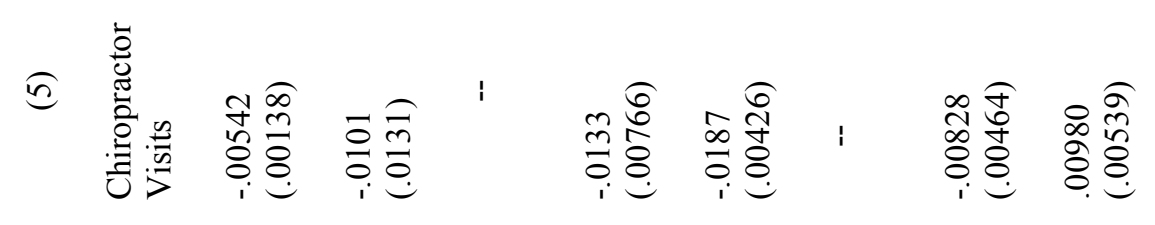

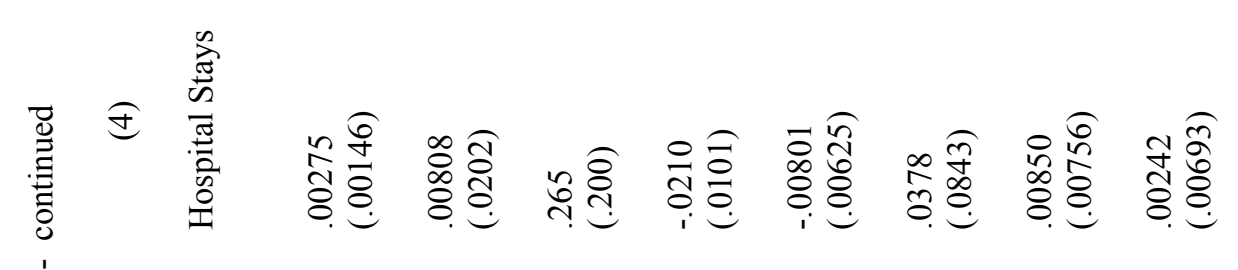

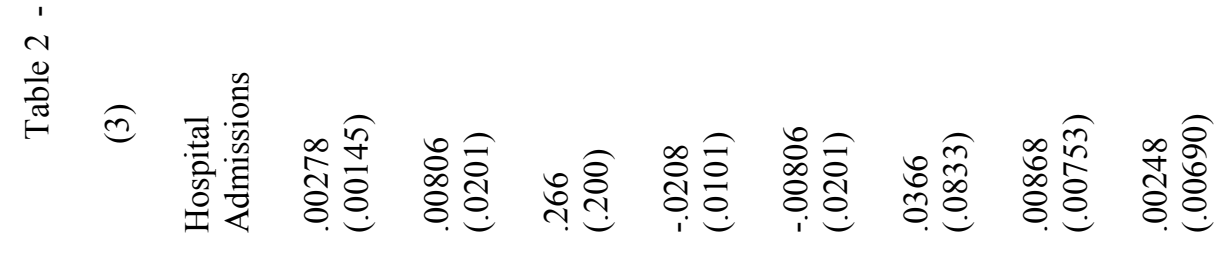

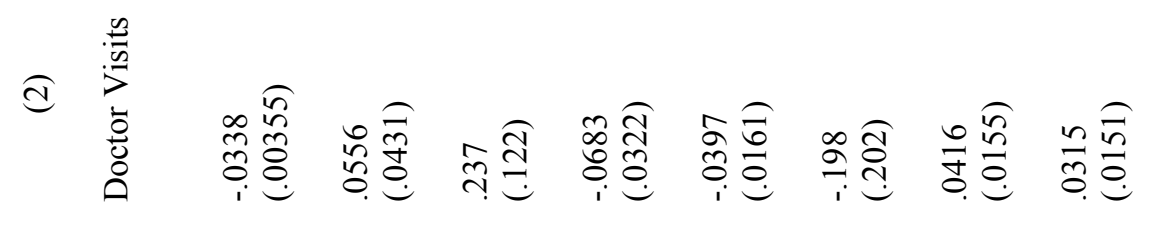

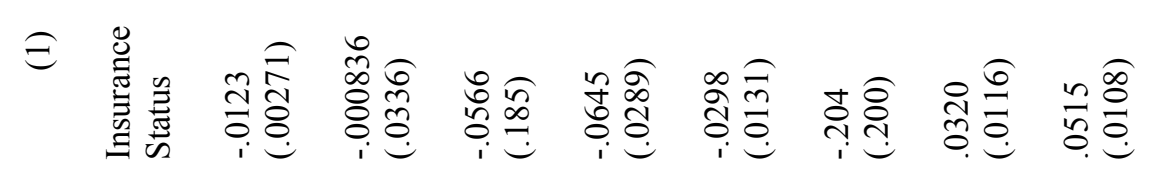

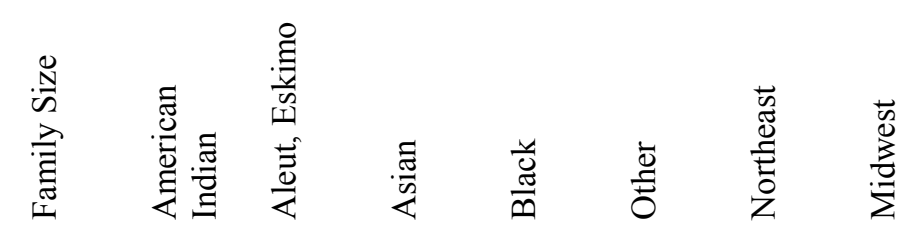


$m$

$$
\begin{aligned}
& \text { 疍岕 } \\
& \text { ํㅡㄹ }
\end{aligned}
$$

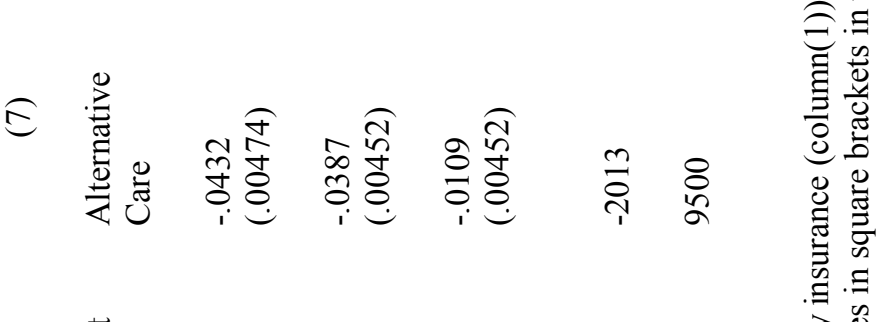

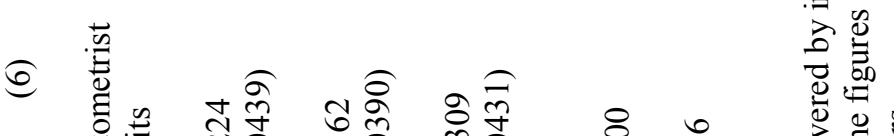

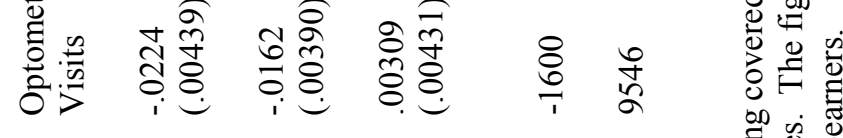

$$
\begin{aligned}
& \text { ot }
\end{aligned}
$$

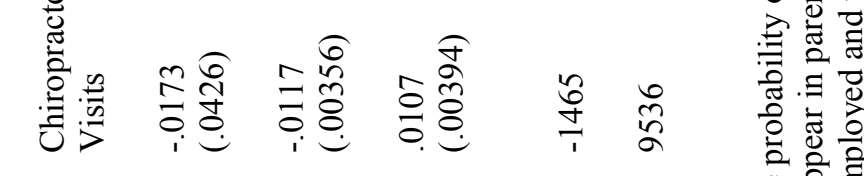

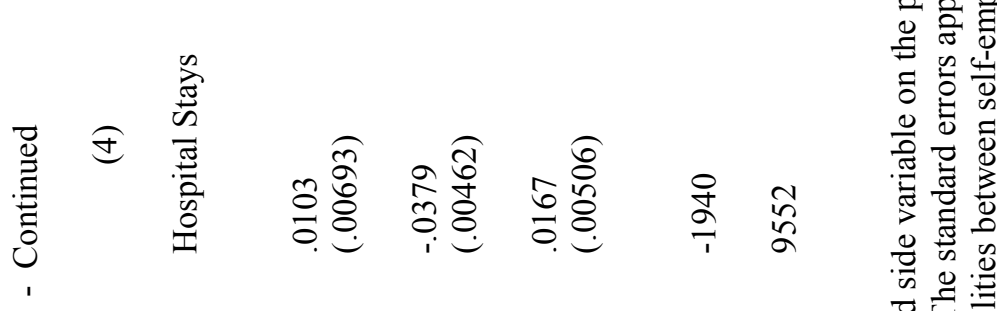

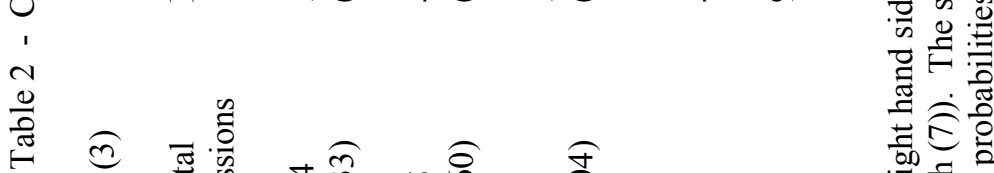

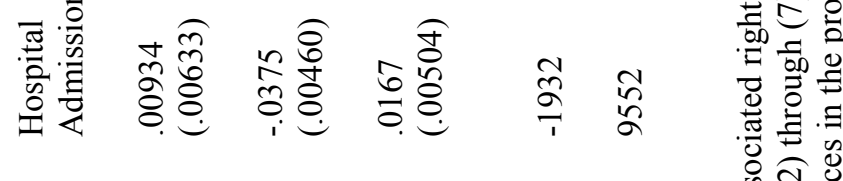

$$
\begin{aligned}
& \text { a } \\
& \text { (ํ) }
\end{aligned}
$$

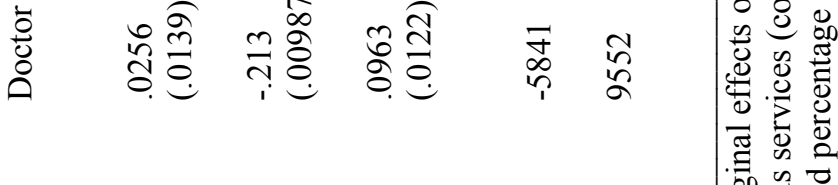

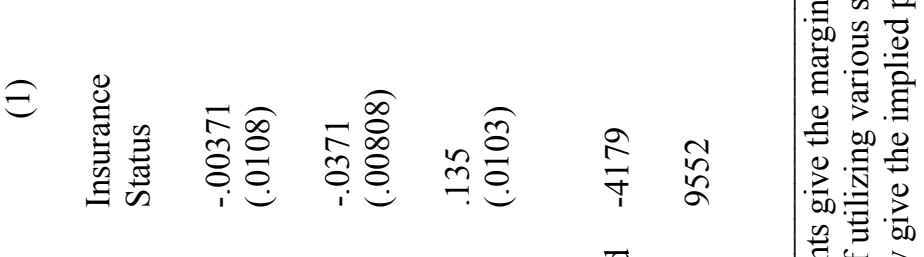

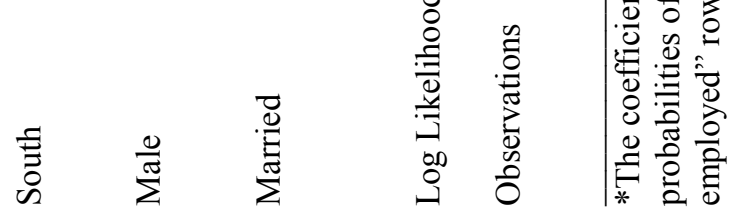


n

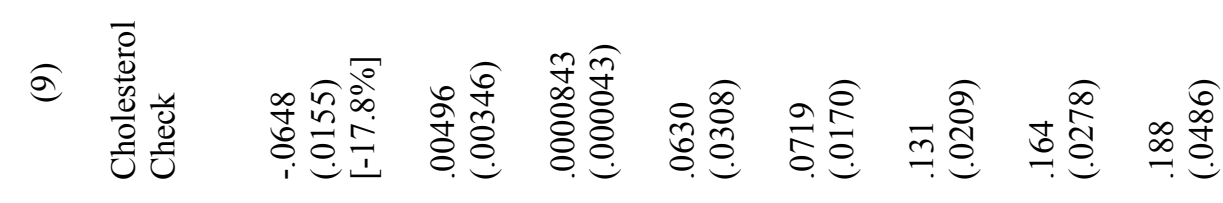

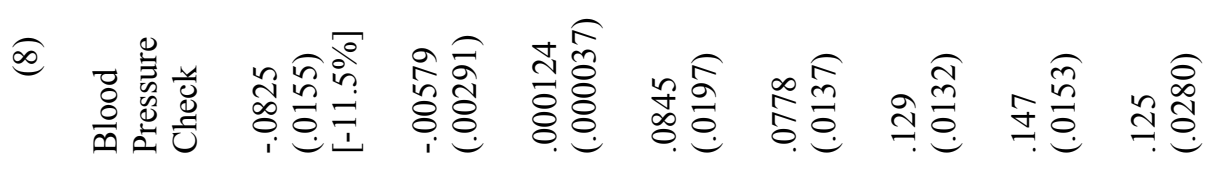

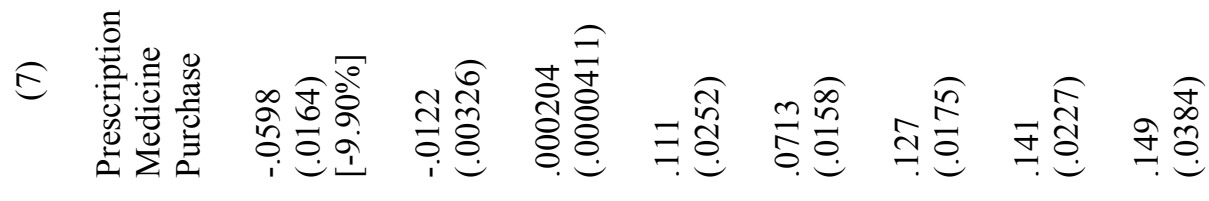

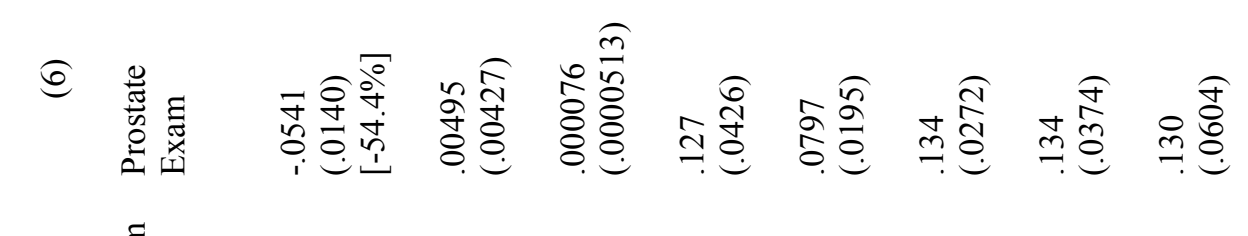

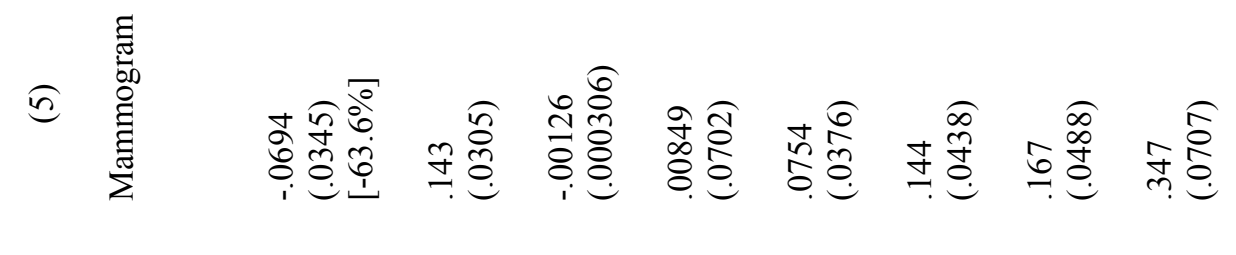

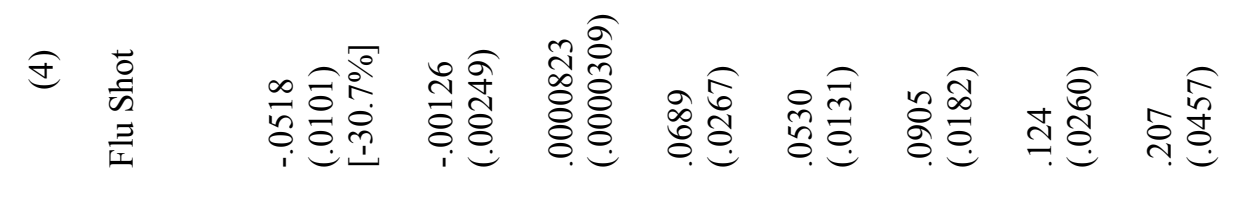

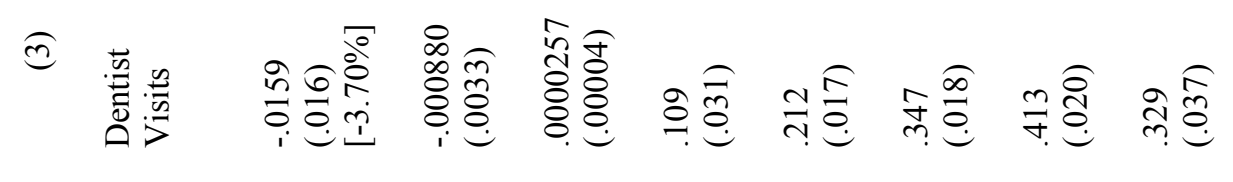

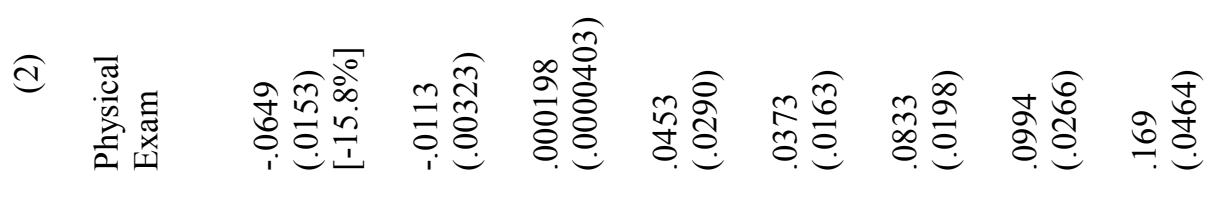

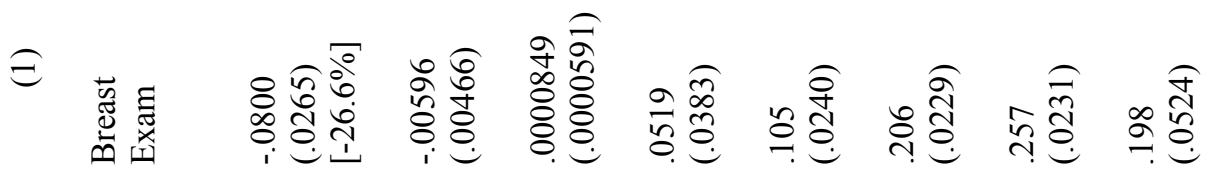

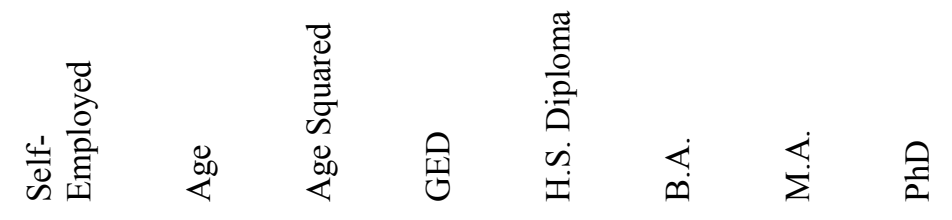


m

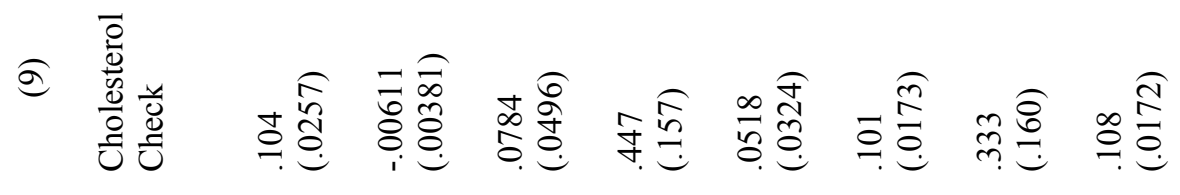

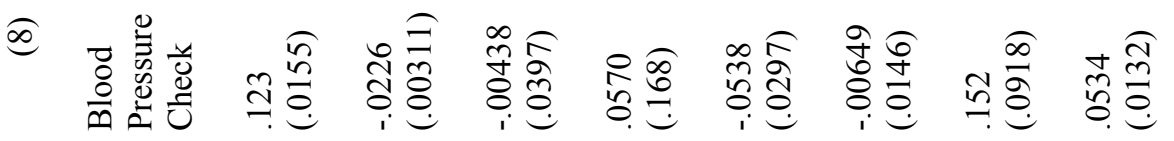

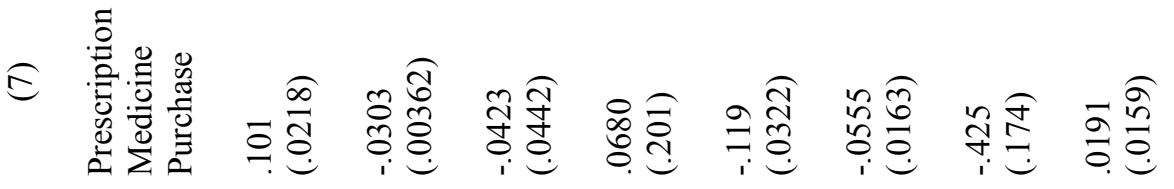

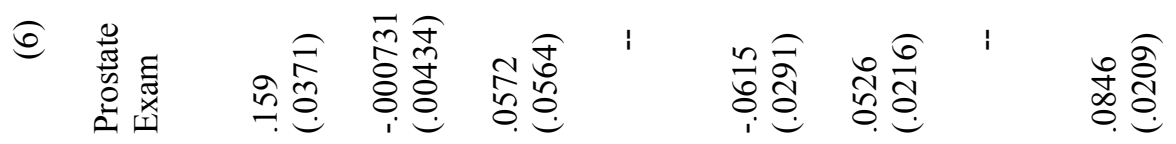

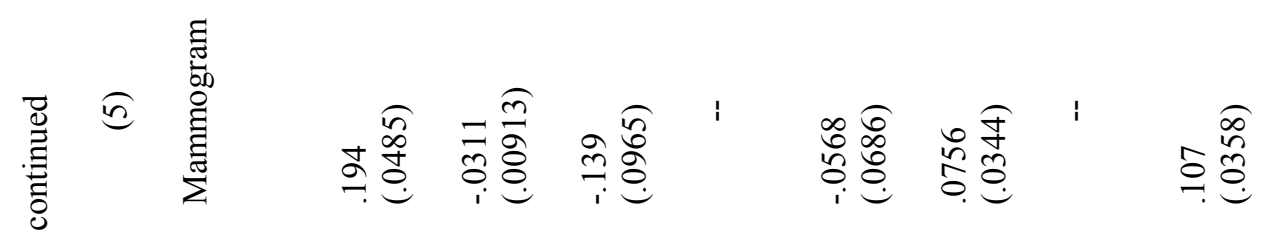

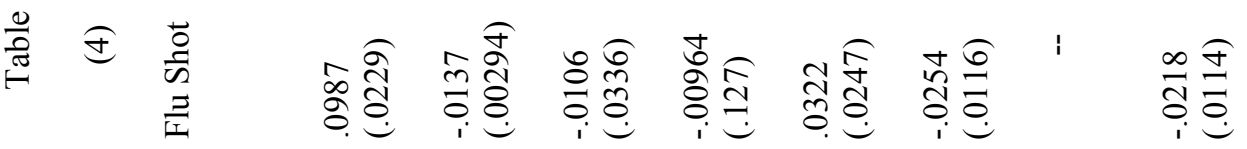

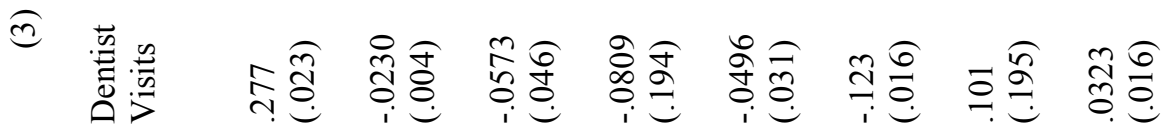

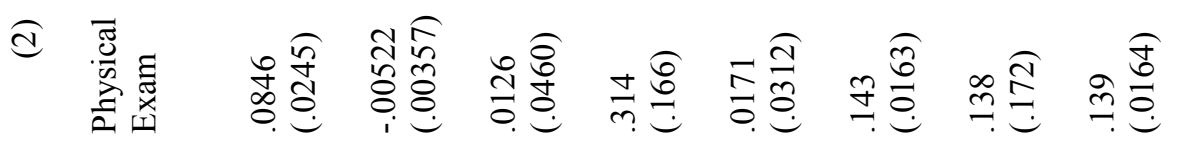

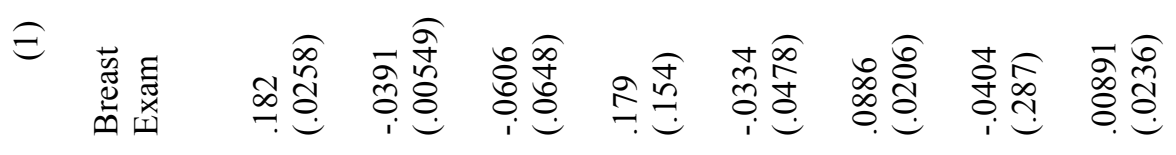

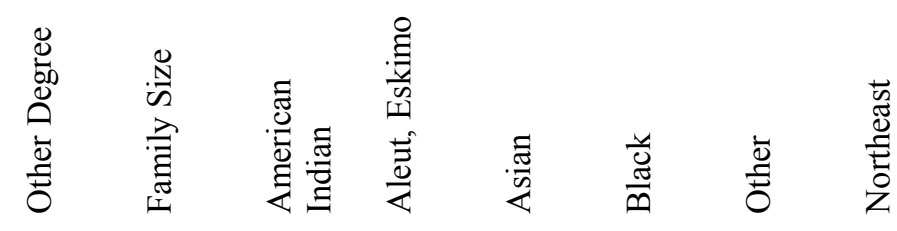


$\infty$

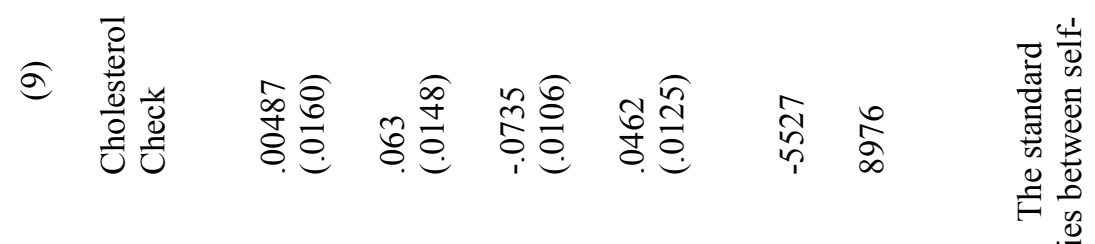

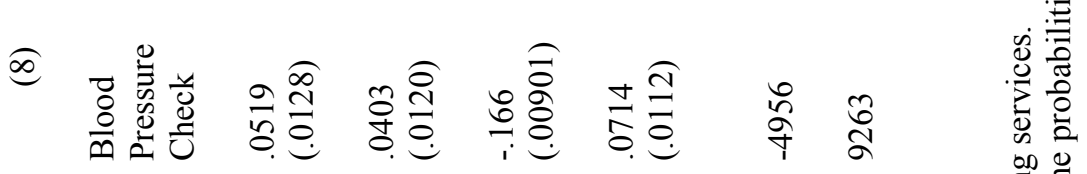

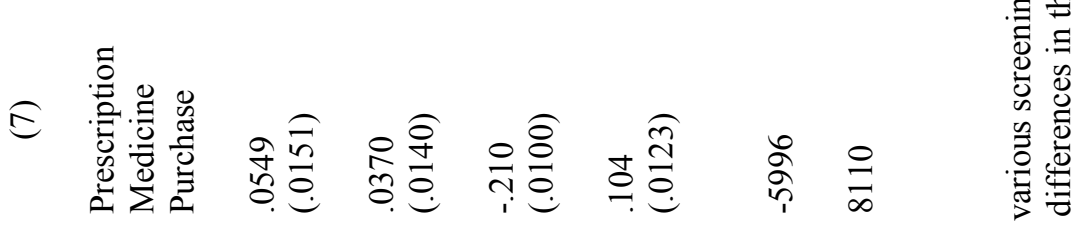

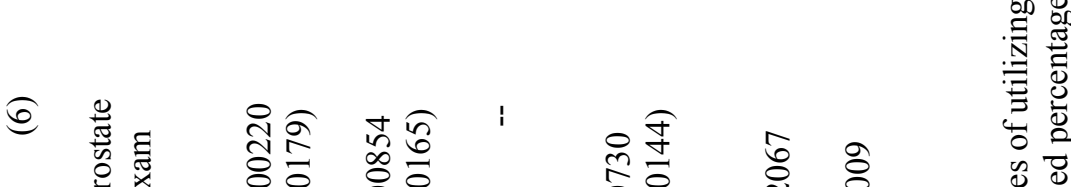

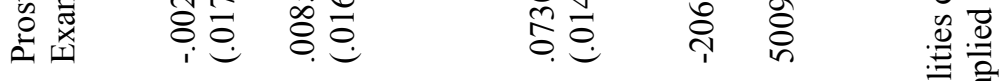

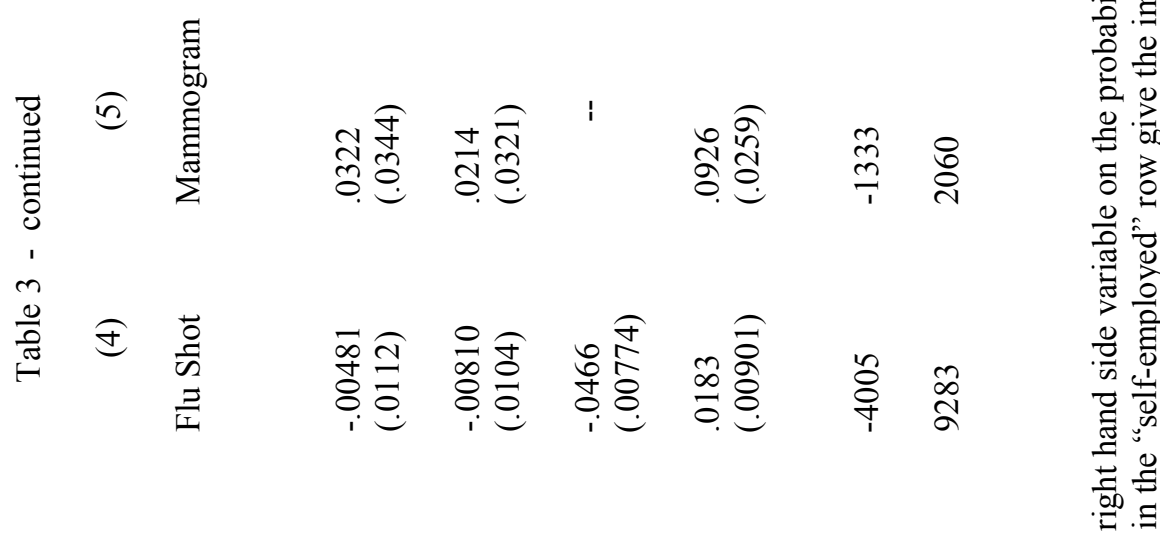

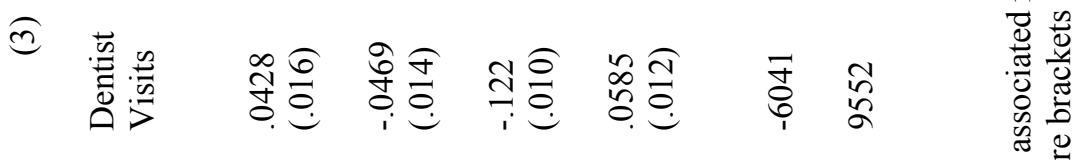

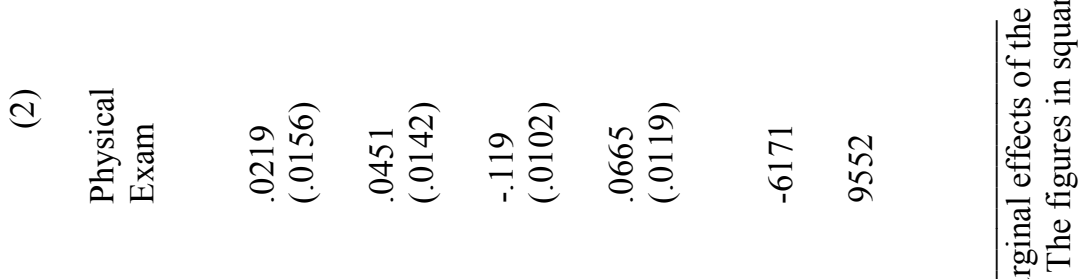

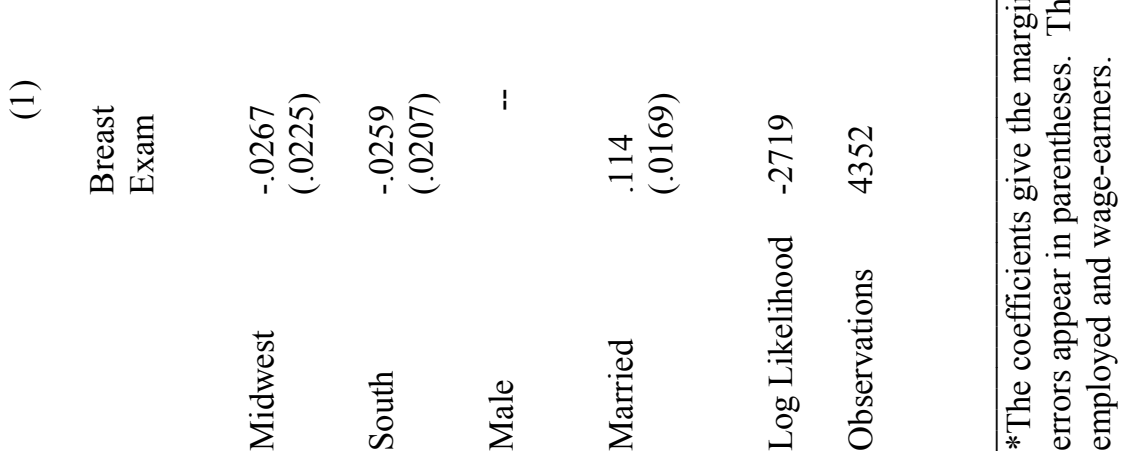


Table 4*

Differential Self-Employment Effects by Organizational Form

$\begin{array}{cccccc}(1) & (2) & (3) & (4) & (5) & (6) \\ \text { Self-employed } & \text { Incorp*SE } & \begin{array}{c}\text { Proprietor- } \\ \text { ship*SE }\end{array} & \text { Test of } & \text { Test of } & \text { Test of } \\ (\delta) & (\gamma) & (\lambda) & \delta=\gamma=\lambda=0 & \delta+\gamma=0 & \delta+\lambda=0\end{array}$

\begin{tabular}{|c|c|c|c|c|c|c|}
\hline $\begin{array}{l}\text { Insurance } \\
\text { Coverage }\end{array}$ & $\begin{array}{l}-0.25 \\
(.045)\end{array}$ & $\begin{array}{l}0.101 \\
(.022)\end{array}$ & $\begin{array}{l}.008 \\
(.25)\end{array}$ & 0.0 & .0018 & 0.0 \\
\hline $\begin{array}{l}\text { Doctor } \\
\text { Visits }\end{array}$ & $\begin{array}{l}-.0853 \\
(.0459)\end{array}$ & $\begin{array}{l}.0201 \\
(.0508)\end{array}$ & $\begin{array}{l}.0324 \\
(.0461)\end{array}$ & 0.0032 & .0277 & .0094 \\
\hline $\begin{array}{l}\text { Hospital } \\
\text { Admissions }\end{array}$ & $\begin{array}{l}-.0235 \\
(.0157)\end{array}$ & $\begin{array}{l}-.0101 \\
(.0231)\end{array}$ & $\begin{array}{l}.0306 \\
(.0333)\end{array}$ & .0623 & .0155 & .7744 \\
\hline Hospital Stays & $\begin{array}{l}-.0167 \\
(.0164)\end{array}$ & $\begin{array}{l}-.0175 \\
(.0188)\end{array}$ & $\begin{array}{l}.0197 \\
(.0280)\end{array}$ & .0840 & .0152 & .8727 \\
\hline $\begin{array}{l}\text { Prescription } \\
\text { Medicine }\end{array}$ & $\begin{array}{l}-.056 \\
(.047)\end{array}$ & $\begin{array}{l}-.022 \\
(.054)\end{array}$ & $\begin{array}{l}.004 \\
(.049)\end{array}$ & 0.0027 & 0.0074 & 0.0089 \\
\hline $\begin{array}{l}\text { Chiropractor } \\
\text { Visits }\end{array}$ & $\begin{array}{l}.032 \\
(.019)\end{array}$ & $\begin{array}{l}-.014 \\
(.009)\end{array}$ & $\begin{array}{l}-.008 \\
(.01)\end{array}$ & 0.008 & 0.4132 & 0.0051 \\
\hline $\begin{array}{l}\text { Optometrist } \\
\text { Visits }\end{array}$ & $\begin{array}{l}.014 \\
(.018)\end{array}$ & $\begin{array}{l}-.012 \\
(.013)\end{array}$ & $\begin{array}{l}-.012 \\
(.012)\end{array}$ & 0.8419 & 0.9615 & 0.9769 \\
\hline $\begin{array}{l}\text { Cholesterol } \\
\text { Check }\end{array}$ & $\begin{array}{l}-.0881 \\
(.0439)\end{array}$ & $\begin{array}{l}.0762 \\
(.0567)\end{array}$ & $\begin{array}{l}.00617 \\
(.0509)\end{array}$ & 0.0001 & 0.5594 & 0.0 \\
\hline Breast Exam & $\begin{array}{l}-0.142 \\
(.0775)\end{array}$ & $\begin{array}{l}.118 \\
(.0761)\end{array}$ & $\begin{array}{l}.0468 \\
(.0742)\end{array}$ & 0.0076 & 0.8913 & 0.0029 \\
\hline $\begin{array}{l}\text { Blood } \\
\text { Pressure } \\
\text { Check }\end{array}$ & $\begin{array}{l}-.170 \\
(.0452)\end{array}$ & $\begin{array}{l}.108 \\
(.0329)\end{array}$ & $\begin{array}{l}.0646 \\
(.0354)\end{array}$ & 0.0 & 0.2512 & 0.0 \\
\hline Physical & $\begin{array}{l}-.0866 \\
(.0428)\end{array}$ & $\begin{array}{l}.0503 \\
(.0541)\end{array}$ & $\begin{array}{l}.0152 \\
(.0492)\end{array}$ & 0.0004 & 0.1677 & 0.0002 \\
\hline $\begin{array}{l}\text { Alternative } \\
\text { Care }\end{array}$ & $\begin{array}{l}.00989 \\
(.0197)\end{array}$ & $\begin{array}{l}.0142 \\
(.0243)\end{array}$ & $\begin{array}{l}.0264 \\
(.0250)\end{array}$ & 0.0 & 0.037 & 0.0 \\
\hline Dentist Visit & $\begin{array}{l}-.0088 \\
(.0436)\end{array}$ & $\begin{array}{l}.0202 \\
(.0520)\end{array}$ & $\begin{array}{l}.00940 \\
(.0473)\end{array}$ & 0.4201 & 0.7938 & 0.1119 \\
\hline
\end{tabular}


Table 4 - continued

(1) Self-employed Incorp*SE

( $)$
(2)

$(\gamma)$
(3) Proprietor-
Ship*SE

$(\lambda)$
(4)

Test of

$$
\delta=\gamma=\lambda=0
$$

0.0

(.0522)

(.0237)

(.0606)

.144

(.112)

.037

$(.060)$
.0703

(.105)

.040

(.058)
0.0041
(5)

Test of Test of $\delta+\lambda=0$

$\begin{array}{llll}\text { Prostate Exam } & -0.081 & .037 & .040 \\ & (.038) & (.060) & (.058)\end{array}$

.0063

.0006

$0.1501 \quad 0.0001$

$0.9558 \quad 0.0592$

0.1313

*These are the results for the self-employment variables when we augment our canonical model with interaction terms to control for differences in organizational form. (See Equation (4.2).) Column (1) gives the effects if the individual is in a partnership; column (2) if incorporated; and column (3) if a sole proprietor. In each cell, the figure is the marginal effect on the probability of the relevant left hand side variable, and the number in parentheses is the standard error. Columns (4) through (6) give the p-values of the associated tests. 